\title{
Macrophages Do Not Express the Phagocytic Receptor BAl1/ADGRB1
}

\author{
Cheng-Chih Hsiao ${ }^{1}$, Marlijn van der Poel' ${ }^{2}$, Tjakko J. van Ham ${ }^{3}$ and Jörg Hamann 1,2* \\ ${ }^{1}$ Department of Experimental Immunology, Amsterdam Infection and Immunity Institute, Amsterdam UMC, University of \\ Amsterdam, Amsterdam, Netherlands, ${ }^{2}$ Department of Neuroimmunology, Netherlands Institute for Neuroscience, \\ Amsterdam, Netherlands, ${ }^{3}$ Department of Clinical Genetics, Erasmus University Medical Center Rotterdam, Rotterdam, \\ Netherlands
}

Keywords: adhesion GPCRs, brain-specific angiogenesis inhibitors, macrophages, microglia, monocytes, phagocytic receptors

The highly organized life of metazoa requires the ability to remove cells that lose their function during embryonic and postnatal development or as part of routine tissue homeostasis $(1,2)$. Normally, these cells undergo programmed, apoptotic cell death, followed by their recognition, engulfment, and, finally, elimination through adjacent tissue cells and/or professional phagocytes. As preeminent phagocytic cells, resident macrophages and circulating monocytes are equipped with an arsenal of receptors that recognize the "eat-me" signals exposed by apoptotic corpses.

OPEN ACCESS

Edited by:

Loems Ziegler-Heitbrock,

Independent Researcher, Munich,

Germany

Reviewed by:

Jean-François Côté,

Institute of Clinical Research De

Montreal (IRCM), Canada

*Correspondence:

Jörg Hamann

j.hamann@amc.uva.nl

Specialty section:

This article was submitted to

Molecular Innate Immunity,

a section of the journal

Frontiers in Immunology

Received: 05 February 2019

Accepted: 15 April 2019

Published: 03 May 2019

Citation:

Hsiao C-C, van der Poel M, van

Ham TJ and Hamann J (2019)

Macrophages Do Not Express the

Phagocytic Receptor BAI1/ADGRB1.

Front. Immunol. 10:962.

doi: 10.3389/fimmu.2019.00962
These phagocytic receptors comprise scavenger receptors, immunoglobulin-containing proteins, and tyrosine kinases (1).

In a Nature paper in 2007, Park et al. described brain-specific angiogenesis inhibitor 1 (BAI1/ADGRB1) as a novel phagocytic receptor on macrophages (3). BAI1 is a member of the adhesion family of G protein-coupled receptors (GPCRs), which in humans comprises 33 non-canonical seven-span transmembrane receptors (4). Adhesion GPCRs possess large $\mathrm{N}$-termini with various protein folds, equipped for (matri)cellular interactions, and a GPCR autoproteolysis-inducing (GAIN) domain that connects the extracellular part of the receptor to the seven-transmembrane region. A juxtamembranous GPCR-proteolysis site (GPS) within the GAIN domain facilitates autocatalytic cleavage of the majority of adhesion GPCRs into two fragments, which remain attached at the cell surface (5). Adhesion GPCRs are found in almost every cell type and adjust modalities in many organ systems. Based on their expression and function, adhesion GPCRs of subfamily E (EMR1/ADGRE1, EMR2/ADGRE2, EMR3/ADGRE3, EMR4/ADGRE4, and CD97/ADGRE5) and subfamily G (GPR56/ADGRG1, GPR97/ADRGRG3, and GPR114/ADGRG5) have been linked to the immune system $(6,7)$. BAI1 belongs to the subfamily B and is abundantly expressed in the brain, where it inhibits angiogenesis and, as recently reported, supports neurogenesis and synaptogenesis (8). The work by Park et al. and others established an additional function of BAI1 in apoptotic cell engulfment by macrophages and their brain equivalent, microglia $(3,9,10)$. Through its $\mathrm{N}$-terminal thrombospondin repeats, BAI1 binds phosphatidylserine, resulting in recruitment of ELMO1 and Dock180 to the C-terminus of the receptor, which function as guanine-exchange factors for Racl and thereby promote engulfment of apoptotic cells. Moreover, expression of BAI1 in primary human monocytes/macrophages and the mouse macrophage cell lines J774 and RAW264.7 was reported (3).

Ingestion of microbes, such as bacteria and fungi, is another phagocytic process executed by macrophages. A subsequent paper in 2011 described the ability of BAI1 to bind and engulf Gram-negative bacteria (11). Interaction of the thrombospondin repeats with bacterial membrane lipopolysaccharide triggered Salmonella engulfment via ELMO1/Dock180, similar to the uptake of 
apoptotic cells. Subsequently, it has been reported that BAI1 mediates macrophage reactive oxygen species production and microbicidal activity through activation of the Rho family guanosine triphosphatase Racl (12). These observations further established BAI1 as a phagocytic receptor of macrophages.

Transcriptome (and proteome) analyses of purified cell populations and, more recently, even single cells is greatly deepening our knowledge about the spatial organization of gene expression. We noticed that omics studies directed at leukocytes consistently detect expression of subfamily $\mathrm{E}$ and $\mathrm{G}$ adhesion GPCRs, but fail to identify subfamily B receptors, including BAI1 $(4,6,7)$. To clarify this discrepancy, we analyzed microarray, CAGE (cap analysis gene expression) and RNA sequencing, and protein mass spectrometry data of primary monocytes, monocytes maturated in vitro under stimulating conditions, macrophage cell lines, as well as bone marrow-derived and primary tissue-derived macrophages. We included all types of monocytes/macrophages, in which Adgrb1/ADGRB1 expression has been reported, with the exception of gastric phagocytes (Table 1). Among other data sets, we evaluated adhesion GPCR transcriptomes (20) and proteomes (23) of classical, intermediate, and non-classical monocytes (Figures 1A,B). Moreover, we examined 299 transcriptomes of monocytes activated with 28 different stimuli, including pattern recognition receptor ligands, cytokines, and metabolic cues (19) (Figure 1C). In none of these and numerous other data sets (Table 1), we obtained evidence that monocytes or monocytederived macrophages express Adgrb1/ADGRB1, while known gene expression patterns of subfamily E adhesion GPCRs were fully confirmed $(6,7)$.

Knowledge of genome-wide gene expression in tissue-resident macrophages, so far, is mainly based on studies in mice. In transcriptomes of seven types of macrophages, Adgrb1 was not detected (25) (Figure 1D). These transcriptomes also included microglia, for which a distinct role for BAI1 in the engulfment of neurons has been described in zebrafish (10). Zebrafish express homologs of most adhesion GPCRs, including BAI1 (34). Yet, by RNA sequencing highly pure microglia from zebrafish, we failed to detect significant levels of Adgrb1 expression (27) (Figure 1D). Similarly, microglia from mouse and human express Adgrg1/ADGRG1, but not Adgrb1/ADGRB1 (24, 28-32) (Figures 1D,E).

We also asked whether unusual mRNA properties, e.g., short poly(A) tails, could have hampered the detection of Adgrb1/ADGRB1 transcripts. To exclude this possibility, we included in our comparison RNA sequencing data obtained by reduction of ubiquitously expressed ribosomal (r)RNAs in combination with random primer amplification $(13,14)$. Moreover, we were able to directly compare sequencing of human microglia RNAs obtained by poly(A) selection and rRNA depletion plus random primer amplification [(32) and Mizee et al., manuscript in preparation], but failed to detect ADGRB1 transcripts with both methods (data not shown).

Abbreviations: BAI, brain-specific angiogenesis inhibitor; GAIN, GPCR autoproteolysis-inducing; GPCR, G protein-coupled receptor; GPS, GPCR-proteolysis site.
Furthermore, Adgrb1/ADGRB1 transcripts are found in mouse and human brain lysate (Figure 1F) as well as in mouse neurons, oligodendrocyte progenitors, and astrocytes (28), confirming their detectability.

Our data do not challenge the role of BAI1 as a phagocytic receptor. This biological activity is based on the binding capacity of the N-terminal thrombospondin repeats for "eatme" signals on apoptotic cells and on the ability of the Cterminal tail to facilitate cytoskeletal rearrangements, and has been proven extensively $(3,11)$. We question, however, that BAI1 is part of the phagocytic machinery of macrophages. The link with macrophages has been established in primary cells and cell lines overexpressing BAI1 in vitro. More recently, Lee at al. investigated the role of BAIl in the dextran sodium sulfate-induced model of colitis in vivo. Adgrb1-deficient mice had more pronounced colitis and lower survival, with many uncleared apoptotic cells and inflammatory cytokines within the colonic epithelium. Notably, transgenic overexpression of Adgrb1 in epithelial, but not in myeloid cells, attenuated colitis severity (35), suggesting that BAI1 mediates clearance of apoptotic corpses within the colonic epithelium. Intestinal epithelial cells may not be the only non-professional phagocytes that engage BAI1. In astrocytes engulfing apoptotic targets, BAI1 showed accumulation within the phagocytic cup (26). Moreover, BAI1 and BAI3 have been described to promote myoblast fusion, a process possibly induced by dying myoblasts $(36,37)$.

In summary, monocytes and macrophages, including microglia, express the adhesion GPCRs EMR1, EMR2, EMR3, CD97, and GPR56 with different species and cell type specificity. BAI1, an adhesion GPCR with diverse and intriguing functions in angiogenesis, neural development, and apoptotic/microbial engulfment, is hardly expressed by

TABLE 1 | Studies reporting and studies failing to find expression of Adgrb 1/ADGRB1 (BAl1) in monocytes/macrophages.

\begin{tabular}{lll}
\hline Cell type & $\begin{array}{l}\text { Reporting } \\
\text { expression }\end{array}$ & Failing to find expression
\end{tabular}

Mouse monocyte/ RT-PCR, IB (3) RNAseq (13-15)
macrophage cell lines

J774A. 1 and

RAW264.7

$\begin{array}{lll}\begin{array}{l}\text { Human monocyte/ } \\ \text { macrophage cell line } \\ \text { THP-1 }\end{array} & \text { RT-PCR, IB (9) } & \begin{array}{l}\text { RNAseq (16, 17) } \\ \text { (http://www.proteinatlas. } \\ \text { org) }\end{array} \\ \begin{array}{l}\text { Monocytes and } \\ \text { monocyte-derived } \\ \text { macrophages }\end{array} & \text { Microarray (18), IB (9) } & \begin{array}{l}\text { Microarray (19), CAGEseq } \\ (20), \text { RNAseq }(17,21,22),\end{array} \\ \begin{array}{l}\text { Bone marrow-derived } \\ \text { macrophages }\end{array} & \text { RT-PCR (11) } & \text { RNAseq }(14,24) \\ \begin{array}{l}\text { Tissue-derived } \\ \text { macrophages }\end{array} & \text { RT-PCR, IB (9) } & \text { RNAseq (24, 25) (https:// } \\ \text { Microglia } & & \text { Www.immgen.org/) } \\ & \text { IHC (26), ISH (10) } & \text { RNAseq (24, 25, 27-32) }\end{array}$

CAGEseq, CAGE sequencing; IB, immunoblot; IHC, immunohistochemistry; ISH, in situ hybridization; MS, mass spectrometry; RNAseq, RNA sequencing; RT-PCR, reverse transcriptase-polymerase chain reaction. 
A

\begin{tabular}{|c|c|c|c|c|c|c|c|c|c|c|c|c|c|c|c|c|c|c|c|c|c|c|c|c|c|c|c|c|c|c|c|c|}
\hline Subfamily & & 1 & & & & & ॥ & & & & III & & & $\mathrm{v}$ & & $\mathrm{v}$ & & & $\mathrm{v}$ & & & & $\mathrm{vI}$ & & & & & VIII & & & & \\
\hline $\begin{array}{l}\text { Gene } \\
\text { rotein) }\end{array}$ & 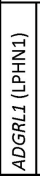 & 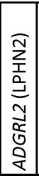 & 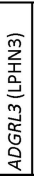 & 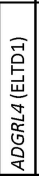 & 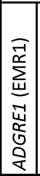 & 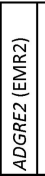 & 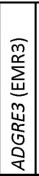 & 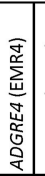 & 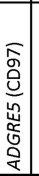 & 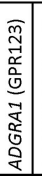 & 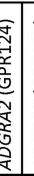 & 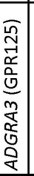 & 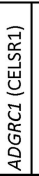 & 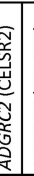 & 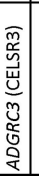 & 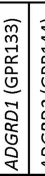 & 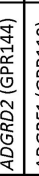 & 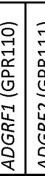 & 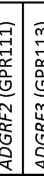 & 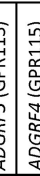 & 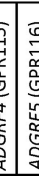 & 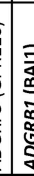 & 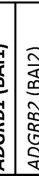 & 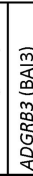 & 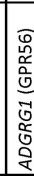 & 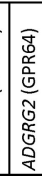 & 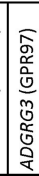 & 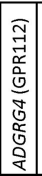 & 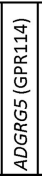 & 0 & 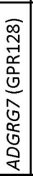 & \\
\hline $\mathrm{CD} 14^{++} \mathrm{CD} 16^{-} \mathrm{cMo}$ & & & & & 33 & 117 & 31 & & 170 & & 7 & & & & & 21 & & & & & & & & 3 & & & 3 & & & & & \\
\hline $\mathrm{CD} 14^{++} \mathrm{CD} 16^{+} \mathrm{iM0}$ & & & & & 88 & 145 & 53 & & 287 & & 3 & & & & & 11 & & & & & & & & 1 & & & 1 & & & & & \\
\hline $\mathrm{CD} 14^{+} \mathrm{CD} 16^{++} \mathrm{nMo}$ & & & & & 174 & & 64 & & 309 & & 1 & & & & & 17 & & & & & & & & & & & 1 & & & & & \\
\hline
\end{tabular}

B

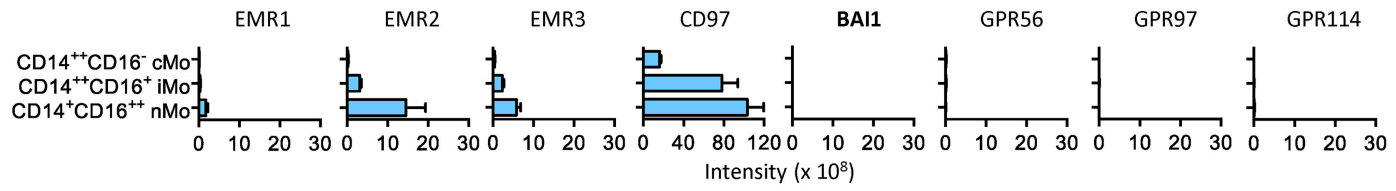

C

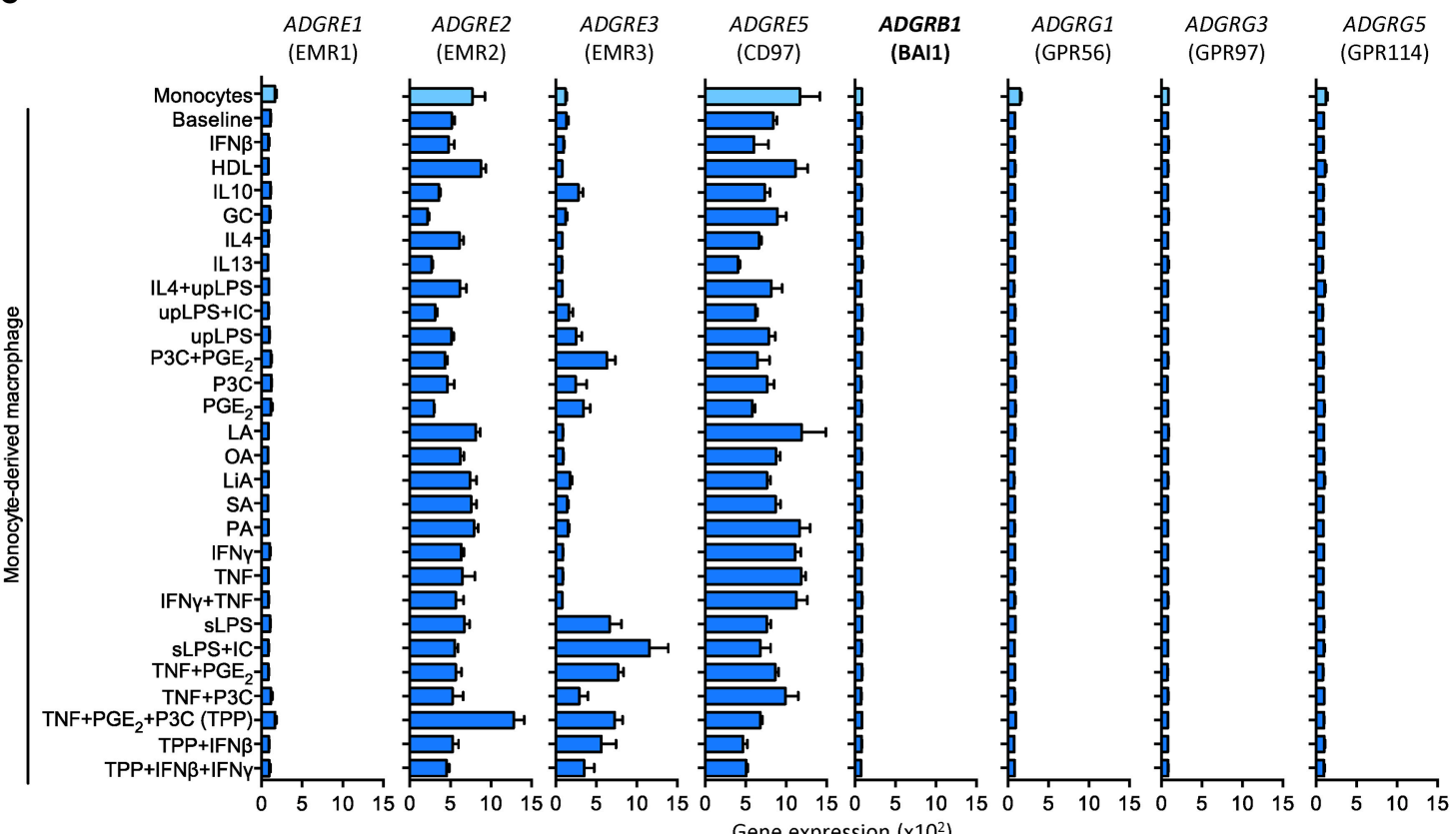

D

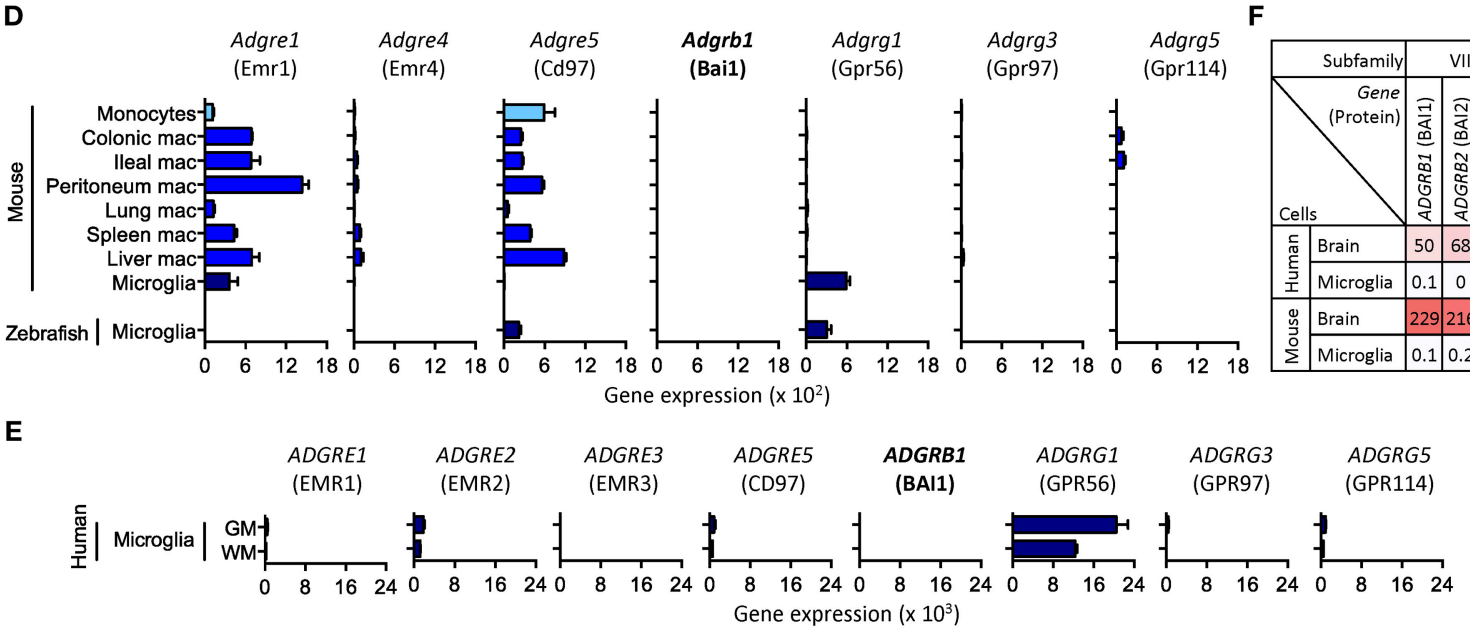

FIGURE 1 | Selected expression profiles of adhesion GPCRs in monocytes, monocyte-derived macrophages, and microglia. (A) CAGE sequencing of circulating human monocytes (20). (B) Protein mass spectrometry of circulating human monocytes (23). (C) Microarray of human monocytes activated with 28 different stimuli 
FIGURE 1 | (19). (D) RNA sequencing of resident mouse macrophages as well as mouse and zebrafish microglia (25, 27). (E) RNA sequencing of resident human grey and white matter (GM and WM) microglia (32). (F) RNA sequencing of mouse and human brain lysates and microglia (30). Note the consistent lack of BAl1 (Adgrb1/ADGRB1) expression in all data sets. Expression of EMR1 to EMR4 (Adgre1/ADGRE1 to Adgre4/ADGRE4) in human and mouse reflect their evolutionary diversification: (i) in contrast to its mouse homolog, F4/80, human EMR1 is weekly expressed by monocytes and macrophages; (ii) mice lack the genes encoding EMR2 and EMR3; (iii) the gene encoding EMR4 has become inactivated in human (33).

professional phagocytes, and we suggest to reassess the link between BAI1 and macrophage biology.

\section{AUTHOR CONTRIBUTIONS}

$\mathrm{C}-\mathrm{CH}, \mathrm{MvdP}, \mathrm{TvH}$, and $\mathrm{JH}$ generated and analyzed data. $\mathrm{C}-\mathrm{CH}$ and $\mathrm{JH}$ wrote the paper.

\section{REFERENCES}

1. Arandjelovic S, Ravichandran KS. Phagocytosis of apoptotic cells in homeostasis. Nat Immunol. (2015) 16:907-17. doi: 10.1038/ni.3253

2. Henson PM. Cell removal: efferocytosis. Annu Rev Cell Dev Biol. (2017) 33:111315-25315. doi: 10.1146/annurev-cellbio-111315-125315

3. Park D, Tosello-Trampont AC, Elliott MR, Lu M, Haney LB, Ma Z, et al. BAIl is an engulfment receptor for apoptotic cells upstream of the ELMO/Dock180/Rac module. Nature. (2007) 450:430-4. doi: $10.1038 /$ nature06329

4. Hamann J, Aust G, Araç D, Engel FB, Formstone C, Fredriksson R, et al. International union of basic and clinical pharmacology. XCIV. Adhesion G protein-coupled receptors. Pharmacol Rev. (2015) 67:338-67. doi: 10.1124/pr.114.009647

5. Prömel S, Langenhan T, Araç D. Matching structure with function: the GAIN domain of adhesion-GPCR and PKD1-like proteins. Trends Pharmacol Sci. (2013) 34:470-8. doi: 10.1016/j.tips.2013.06.002

6. Hamann J, Hsiao CC, Lee CS, Ravichandran KS, Lin HH. Adhesion GPCRs as modulators of immune cell function. Handb Exp Pharmacol. (2016) 234:32950. doi: 10.1007/978-3-319-41523-9_15

7. Lin H-H, Hsiao C-C, Pabst C, Hébert J, Schöneberg T, Hamann J. Adhesion GPCRs in regulating immune responses and inflammation. Adv Immunol. (2017) 136:163-201. doi: 10.1016/bs.ai.2017.05.005

8. Stephenson JR, Purcell RH, Hall RA. The BAI subfamily of adhesion GPCRs: synaptic regulation and beyond. Trends Pharmacol Sci. (2014) 35:208-15. doi: 10.1016/j.tips.2014.02.002

9. Das S, Sarkar A, Ryan KA, Fox S, Berger AH, Juncadella IJ, et al. Brain angiogenesis inhibitor 1 is expressed by gastric phagocytes during infection with Helicobacter pylori and mediates the recognition and engulfment of human apoptotic gastric epithelial cells. FASEB J. (2014) 28:2214-24. doi: 10.1096/fj.13-243238

10. Mazaheri F, Breus O, Durdu S, Haas P, Wittbrodt J, Gilmour D, et al. Distinct roles for BAI1 and TIM-4 in the engulfment of dying neurons by microglia. Nat Commun. (2014) 5:4046. doi: 10.1038/ncomms5046

11. Das S, Owen KA, Ly KT, Park D, Black SG, Wilson JM, et al. Brain angiogenesis inhibitor 1 (BAI1) is a pattern recognition receptor that mediates macrophage binding and engulfment of Gram-negative bacteria. Proc Natl Acad Sci USA. (2011) 108:2136-41. doi: 10.1073/pnas.1014775108

12. Billings EA, Lee CS, Owen KA, D'Souza RS, Ravichandran KS, Casanova JE. The adhesion GPCR BAIl mediates macrophage ROS production and microbicidal activity against Gram-negative bacteria. Sci Signal. (2016) 9:ra14. doi: 10.1126/scisignal.aac6250

13. Schott J, Reitter S, Philipp J, Haneke K, Schäfer H, Stoecklin G. Translational regulation of specific mRNAs controls feedback inhibition and survival during macrophage activation. PLoS Genet. (2014) 10:e1004368. doi: 10.1371/journal.pgen.1004368

14. Das A, Yang C-S, Arifuzzaman S, Kim S, Kim SY, Jung KH, et al. Highresolution mapping and dynamics of the transcriptome, transcription factors,

\section{ACKNOWLEDGMENTS}

We thank Mark Mizee for sharing unpublished data and Tobias Langenhan for helpful comments. The study was supported by grants from the Thyssen Foundation (2015-00387), the MS Research Foundation (MS13-830), and the German Research Foundation (FOR 2149).

and transcription co-factor networks in classically and alternatively activated macrophages. Front Immunol. (2018) 9:22. doi: 10.3389/fimmu.2018. 00022

15. Andreu N, Phelan J, de Sessions PF, Cliff JM, Clark TG, Hibberd ML. Primary macrophages and J774 cells respond differently to infection with Mycobacterium tuberculosis. Sci Rep. (2017) 7:42225. doi: 10.1038/srep42225

16. Phanstiel DH, Van Bortle K, Spacek D, Hess GT, Shamim MS, Machol I, et al. Static and dynamic DNA loops form AP-1-bound activation hubs during macrophage development. Mol Cell. (2017) 67:1037-48.e6. doi: 10.1016/j.molcel.2017.08.006

17. Liu H, Lorenzini PA, Zhang F, Xu S, Wong MSM, Zheng J, et al. Alternative splicing analysis in human monocytes and macrophages reveals MBNL1 as major regulator. Nucleic Acids Res. (2018) 46:6069-86. doi: 10.1093/nar/gky401

18. Cho HJ, Shashkin P, Gleissner CA, Dunson D, Jain N, Lee JK, et al. Induction of dendritic cell-like phenotype in macrophages during foam cell formation. Physiol Genomics. (2007) 29:149-60. doi: 10.1152/physiolgenomics.00051.2006

19. Xue J, Schmidt SV, Sander J, Draffehn A, Krebs W, Quester I, et al. Transcriptome-based network analysis reveals a spectrum model of human macrophage activation. Immunity. (2014) 40:274-88. doi: 10.1016/j.immuni.2014.01.006

20. Schmidl C, Renner K, Peter K, Eder R, Lassmann T, Balwierz PJ, et al. Transcription and enhancer profiling in human monocyte subsets. Blood. (2014) 123:e90-9. doi: 10.1182/blood-2013-02-484188

21. Schmiedel BJ, Singh D, Madrigal A, Valdovino-Gonzalez AG, White $\mathrm{BM}$, Zapardiel-Gonzalo J, et al. Impact of genetic polymorphisms on human immune cell gene expression. Cell. (2018) 175:1701-15.e16. doi: $10.1016 /$ j.cell.2018.10.022

22. Monaco G, Lee B, Xu W, Mustafah S, Hwang YY, Carré C, et al. RNA-Seq signatures normalized by mRNA abundance allow absolute deconvolution of human immune cell types. Cell Rep. (2019) 26:1627-40.e7. doi: 10.1016/j.celrep.2019.01.041

23. Rieckmann JC, Geiger R, Hornburg D, Wolf T, Kveler K, Jarrossay D, et al. Social network architecture of human immune cells unveiled by quantitative proteomics. Nat Immunol. (2017) 18:583-93. doi: 10.1038/ni.3693

24. Gosselin D, Link VM, Romanoski CE, Fonseca GJ, Eichenfield DZ, Spann NJ, et al. Environment drives selection and function of enhancers controlling tissue-specific macrophage identities. Cell. (2014) 159:1327-40. doi: 10.1016/j.cell.2014.11.023

25. Lavin Y, Winter D, Blecher-Gonen R, David E, Keren-Shaul H, Merad M, et al. Tissue-resident macrophage enhancer landscapes are shaped by the local microenvironment. Cell. (2014) 159:1312-26. doi: 10.1016/j.cell.2014.11.018

26. Sokolowski JD, Nobles SL, Heffron DS, Park D, Ravichandran KS, Mandell JW. Brain-specific angiogenesis inhibitor-1 expression in astrocytes and neurons: implications for its dual function as an apoptotic engulfment receptor. Brain Behav Immun. (2011) 25:915-21. doi: 10.1016/j.bbi.2010.09.021 
27. Oosterhof N, Holtman IR, Kuil LE, van der Linde HC, Boddeke EWGM, Eggen BJL, et al. Identification of a conserved and acute neurodegenerationspecific microglial transcriptome in the zebrafish. Glia. (2017) 65:138-49. doi: 10.1002/glia.23083

28. Zhang Y, Chen K, Sloan SA, Bennett ML, Scholze AR, O'Keeffe S, et al. An RNA-sequencing transcriptome and splicing database of glia, neurons, and vascular cells of the cerebral cortex. J Neurosci. (2014) 34:11929-47. doi: 10.1523/JNEUROSCI.1860-14.2014

29. Keren-Shaul H, Spinrad A, Weiner A, Matcovitch-Natan O, DvirSzternfeld R, Ulland TK, et al. A unique microglia type associated with restricting development of Alzheimer's disease. Cell. (2017) 169:1276-90.e17. doi: 10.1016/j.cell.2017.05.018

30. Gosselin D, Skola D, Coufal NG, Holtman IR, Schlachetzki JCM, Sajti E, et al. An environment-dependent transcriptional network specifies human microglia identity. Science. (2017) 356:eaal3222. doi: 10.1126/science.aal3222

31. Galatro TF, Holtman IR, Lerario AM, Vainchtein ID, Brouwer N, Sola PR, et al. Transcriptomic analysis of purified human cortical microglia reveals ageassociated changes. Nat Neurosci. (2017) 20:1162-71. doi: 10.1038/nn.4597

32. van der Poel M, Ulas T, Mizee MR, Hsiao C-C, Miedema SSM, Schuurman $\mathrm{KG}$, et al. Transcriptional profiling of human microglia reveals grey-white matter heterogeneity and multiple sclerosis-associated changes. Nat Commun. (2019) 10:1139. doi: 10.1038/s41467-019-08976-7

33. Gordon S, Hamann J, Lin HH, Stacey M. F4/80 and the related adhesionGPCRs. Eur J Immunol. (2011) 41:2472-6. doi: 10.1002/eji.201141715

34. Harty BL, Krishnan A, Sanchez NE, Schiöth HB, Monk KR. Defining the gene repertoire and spatiotemporal expression profiles of adhesion
G protein-coupled receptors in zebrafish. BMC Genomics. (2015) 16:62. doi: 10.1186/s12864-015-1296-8

35. Lee CS, Penberthy KK, Wheeler KM, Juncadella IJ, Vandenabeele P, Lysiak JJ, et al. Boosting Apoptotic cell clearance by colonic epithelial cells attenuates inflammation in vivo. Immunity. (2016) 44:807-20. doi: 10.1016/j.immuni.2016.02.005

36. Hochreiter-Hufford AE, Lee CS, Kinchen JM, Sokolowski JD, Arandjelovic S, Call JA, et al. Phosphatidylserine receptor BAI1 and apoptotic cells as new promoters of myoblast fusion. Nature. (2013) 497:263-7. doi: $10.1038 /$ nature 12135

37. Hamoud N, Tran V, Croteau L-P, Kania A, Côté J-F. G-protein coupled receptor BAI3 promotes myoblast fusion in vertebrates. Proc Natl Acad Sci USA. (2014) 111:3745-50. doi: 10.1073/pnas.1313 886111

Conflict of Interest Statement: The authors declare that the research was conducted in the absence of any commercial or financial relationships that could be construed as a potential conflict of interest.

Copyright (C) 2019 Hsiao, van der Poel, van Ham and Hamann. This is an open-access article distributed under the terms of the Creative Commons Attribution License (CC $B Y)$. The use, distribution or reproduction in other forums is permitted, provided the original author(s) and the copyright owner(s) are credited and that the original publication in this journal is cited, in accordance with accepted academic practice. No use, distribution or reproduction is permitted which does not comply with these terms. 